\title{
Treatment outcomes of oral sitafloxacin in acute complicated urinary tract infection and pyelonephritis
}

Weerawat Manosuthi* and Surasak Wiboonchutikul

\begin{abstract}
Background: Data on the success rate of sitafloxacin treatment in acute complicated urinary tract infection and pyelonephritis are limited.

Objectives: To determine the success rate of a new oral fluoroquinolone, sitafloxacin, in acute complicated urinary tract infection and pyelonephritis.

Methods: A prospective study of 30 patients who were diagnosed with acute complicated urinary tract infection and pyelonephritis was conducted. Oral sitafloxacin $50 \mathrm{mg}$ twice a day was given for 7 days. All patients were followed up at baseline, day 7, and day 14.

Results: The patient sample included $67 \%$ females; the mean \pm SD age was $49 \pm 13$ years. Twenty-one (70\%) patients had acute pyelonephritis and $9(30 \%)$ had complicated urinary tract infections. Twenty-two patients were positive for uropathogens. The most frequently isolated pathogen was $E$. coli 11 non-extended spectrum beta-lactamase (ESBL) producing and 5 ESBL-producing strains. Of the 22 isolated uropathogens, 19 (86 \%) isolates were sensitive to sitafloxacin. At day 14, 29 of 30 (97\%) were clinically cured and 21 of 22 (95\%) were microbiologically cured. No patients discontinued sitafloxacin due to adverse events.
\end{abstract}

Conclusions: These results support the use of oral sitafloxacin in complicated urinary tract infections and acute pyelonephritis. However, further larger studies are required to confirm these results.

Keywords: Sitafloxacin, Urinary tract infection, Pyelonephritis, Treatment

\section{Impacts of findings on practice statements}

- Oral sitafloxacin demonstrated high rates of microbiological success in the treatment of acute complicated UTI and pyelonephritis.

- Oral sitafloxacin demonstrated high rates of clinical success in the treatment of acute complicated UTI and pyelonephritis.

- Overall tolerability profile of sitafloxacin is favorable.

\section{Background}

Complicated urinary tract infections and acute pyelonephritis are relatively common infectious genitourinary

*Correspondence: drweerawat@hotmail.com

Department of Medicine, Bamrasnaradura Infectious Diseases Institute,

Ministry of Public Health, Tiwanon Road, Nonthaburi 11000, Thailand problems. A complicated urinary tract infection localizes to the lower or upper urinary tract and is related to structural or functional abnormalities that may increase the risk of treatment failure, urinary tract obstruction and urinary bladder dysfunction (Grabe et al. 2013). Acute pyelonephritis is commonly described as an infection of the upper urinary tract that includes fever and flank pain. It is an exudative purulent localized inflammation of the renal pelvis and kidney (Grabe et al. 2013). These are potentially serious infections that require prompt and effective antibiotic therapy. Renally excreted fluoroquinolones, such as levofloxacin and ciprofloxacin, are frequently prescribed for treatment (Hooton 2003). For patients who can tolerate oral therapy, empiric treatment with an oral fluoroquinolone is an optimal treatment. Fluoroquinolones used to previously treat urinary tract
Springer Open

(c) 2016 Manosuthi and Wiboonchutikul. This article is distributed under the terms of the Creative Commons Attribution 4.0 International License (http://creativecommons.org/licenses/by/4.0/), which permits unrestricted use, distribution, and reproduction in any medium, provided you give appropriate credit to the original author(s) and the source, provide a link to the Creative Commons license, and indicate if changes were made. 
infections include ciprofloxacin, levofloxacin, norfloxacin and ofloxacin (Gupta et al. 2011; Singh et al. 2013). A previous study of 28 hospitals in Thailand showed that $44 \%$ of Escherichia coli isolated from the urine was resistant to ciprofloxacin and found a correlation between the incidence of ciprofloxacin-resistant $E$. coli bacteremia and the upward trend in quinolone use in the community (Polwichai et al. 2009). In 2008, sitafloxacin, a potent broad-spectrum oral fluoroquinolone, was launched (Keating 2011). This drug is mainly renally excreted as an unchanged drug (Payne et al. 2005; O'Grady et al. 2001). Sitafloxacin possesses activity against a variety of uropathogens, including E. coli (Keating 2011). Based on susceptibility rates, the activity of sitafloxacin against $E$. coli appeared greater than that of levofloxacin or ciprofloxacin. The bioavailability of sitafloxacin is $100 \%$, and food intake does not affect the pharmacokinetics of this drug to a significant extent (Nakashima et al. 1995). Approximately $80 \%$ of sitafloxacin was excreted in the urine within $72 \mathrm{~h}$ of administration (Keating 2011). Oral sitafloxacin $50 \mathrm{mg}$ twice daily was considered an effective dosage in patients with complicated urinary tract infections (Keating 2011). For the patients suspected of having a poor response to the usual dose, the dosage may be increased to $100 \mathrm{mg}$ twice daily and extended to a 14-day period. To date, data regarding the success rate of sitafloxacin in acute complicated urinary tract infection and pyelonephritis are relatively limited. In addition, the causative uropathogens may vary in each geographic area. Thus, the objective of this study was to examine the treatment's success rate in Thai patients diagnosed with acute complicated urinary tract infection and pyelonephritis.

\section{Methods}

The present study was designed as a pilot prospective single-arm study involving 30 patients at the Bamrasnaradura Infectious Diseases Institute, Ministry of Public Health, Nonthaburi, Thailand. This trial was performed in compliance with the Declaration of Helsinki and approved by the institutional review boards. Written informed consent was obtained from every patient before the initiation of the study procedures. The period of enrolment was from November 2013 to October 2014. The primary objective was to study the rate of microbiological eradication in patients at day 14 . The secondary objectives were to study microbiological eradication at day 7 , clinical success at day 14 , and the tolerability to sitafloxacin. Inclusion criteria were as follows: (1) patients who were 18-70 years of age, (2) those with complicated urinary tract infections or acute pyelonephritis, and (3) those who participated and provided informed consent. A complicated urinary tract infection was defined as a urinary infection occurring in a patient with a structural or functional abnormality of the genitourinary tract, urinary tract stone, urinary tract obstruction, neurogenic bladder, or indwelling urethral catheter, for example. Exclusion criteria were as follows: (1) patients who could not tolerate oral therapy, (2) those having significant immune deficiency, such as receiving chemotherapy or having human immune deficiency virus infection, (3) having septic shock or unstable vital signs, (4) having prostatitis, perinephric abscess, or intra-renal abscess, (5) history of allergy to fluoroquinolones, (6) underlying diabetes mellitus, (7) history of epilepsy, and (8) myasthenia gravis. Prostatitis was excluded by a historical and physical examination, including digital rectal examination and ultrasonography. One dose of systemic intravenous antibiotic treatment was allowed within $24 \mathrm{~h}$ prior to enrolment, including a third-generation cephalosporin or aminoglycoside.

All eligible patients received oral sitafloxacin $50 \mathrm{mg}$ twice a day for 7 days. The treatment period was extended up to 14 days, depending on the treatment response, including the delayed resolution of fever and/ or symptoms for more than 5 days. The dosage was increased from $50 \mathrm{mg}$ twice a day to $100 \mathrm{mg}$ twice a day in cases of clinical improvement, despite the sensitivity indicating sitafloxacin resistance. The patients had follow-up visits at day 7 and day 14 after initiation of sitafloxacin, at which time they were assessed clinically and blood samples were taken. Patients provided midstream urine samples for examination; these were sent for culture before the first dose of study medication and subsequent visits. Urine samples were obtained by straight catheterization if urine catheters were placed. Levels of $>10^{5} \mathrm{CFU} / \mathrm{mL}$ uropathogens in midstream urine in women, $>10^{4} \mathrm{CFU} / \mathrm{mL}$ in midstream urine in men, or in straight catheter urine in women, were considered to be significant uropathogens in complicated urinary tract infections. A level of $>10^{4} \mathrm{CFU} / \mathrm{mL}$ uropathogens in midstream urine was considered to be significant in acute uncomplicated pyelonephritis in women. In vitro susceptibility tests of sitafloxacin were performed by the disk diffusion method. Escherichia coli ATCC25922, Pseudomonas aeruginosa ATCC 27853, and Enterococcus faecalis ATCC29212 were used as reference strains. Inhibition zone diameters $\geq 19 \mathrm{~mm}$ and $\leq 15 \mathrm{~mm}$ were the breakpoints for susceptibility for sensitive and resistant gram-negative uropathogens and gram-positive uropathogens isolated from urine. An inhibition zone diameter $>15$ to $<19 \mathrm{~mm}$ was an intermediate breakpoint for these uropathogens.

Laboratory parameters, including complete blood cell count, kidney enzymes, erythrocyte sedimentation rate (ESR), C-reactive protein (CRP), and liver enzymes were 
assessed at the baseline visit and on day 7 . The dosage of sitafloxacin was $50 \mathrm{mg}$ per day for patients with estimated glomerular filtration rate (eGFR) $\geq 30$ to $<50 \mathrm{~mL} /$ $\min / 1.73 \mathrm{~m}^{2}$ and $50 \mathrm{mg}$ every other day for patients with eGFR 10 to $<30 \mathrm{~mL} / \mathrm{min} / 1.73 \mathrm{~m}^{2}$. The eGFR was calculated by the Modification in Diet in Renal Disease (MDRD). The eGFR MDRD was calculated as the following: $186 \times$ serum creatinine ${ }^{-1.154} \times$ age $^{-0.203} \times(0.742$ if female). Subjects whose initial uropathogens were resistant to sitafloxacin could remain in the study if they improved clinically; in this case, they were included in the analysis. In such cases, the dosage of sitafloxacin was adjusted to $100 \mathrm{mg}$ twice daily. Clinical cure was assessed by the investigator and defined as resolution of initial clinical signs and symptoms without antibiotic treatment. Microbiological response was assessed according to results of the urine culture at follow-up visits. "Microbiological cure" was assigned to patients whose urine culture demonstrated elimination of their study entry uropathogens. At day 14, patients were assigned a response of "presumed microbiological cure" if a urine culture was not available at day 14 but a microbiological cure at day 7 combined with a clinical cure at day 14 was documented. Adverse events included events reported by patients and those observed as laboratory abnormalities.

The analyses were performed using the intention-totreat principle. Frequencies and the mean \pm SD were used to describe clinical variables and laboratory variables. The paired $t$ test was used to compare means of variables between the baseline visit and day 7. A $P$ value $<0.05$ was considered statistically significant. All analyses were performed using SPSS version 15.0 (SPSS Inc., Chicago, IL, USA).

\section{Results}

Table 1 shows the baseline characteristics of 30 patients. Of the total, $67 \%$ were female; the mean \pm SD age was $49 \pm 13$ years. Sixty percent of patients were treated with outpatient antibiotic therapy and $40 \%$ received inpatient therapy. Twenty-one $(70 \%)$ patients had acute pyelonephritis, and $9(30 \%)$ had complicated urinary tract infections. Twenty-two patients had positive uropathogens. The most frequently isolated pathogens included 11 nonextended spectrum beta-lactamase (ESBL)-producing $E$. coli and 5 ESBL-producing E. coli. Of 22 isolated uropathogens, $19(86 \%)$ isolates were sensitive to sitafloxacin. Two sitafloxacin-resistant isolates included Enterobacter cloacae and Klebsiella pneumoniae and one sitafloxacinintermediate isolate was methicillin-resistant Staphylococcus aureus (MRSA). Among 16 isolates with E. coli, including 11 non- ESBL producing strains and 5 ESBLproducing strains, all were sensitive to sitafloxacin. All 5 ESBL-producing strains were resistant to ciprofloxacin,
Table 1 Baseline characteristics of 30 patients

\begin{tabular}{|c|c|}
\hline Parameters & Number (\%) \\
\hline \multicolumn{2}{|l|}{ Patients' parameters } \\
\hline \multicolumn{2}{|l|}{ Sex } \\
\hline Male & $10(33 \%)$ \\
\hline Female & $20(67 \%)$ \\
\hline Age, years, mean $\pm S D$ & $49 \pm 13$ \\
\hline Body weight, kg, mean \pm SD & $62 \pm 12$ \\
\hline \multicolumn{2}{|l|}{ Laboratory parameters } \\
\hline Hematocrit, mg \%, mean \pm SD & $37 \pm 6$ \\
\hline White blood cells count, cells $/ \mathrm{mm}^{3}$, mean $\pm \mathrm{SD}$ & $11,340 \pm 5,496$ \\
\hline Platelet, cells $/ \mathrm{mm}^{3}$, mean $\pm \mathrm{SD}$ & $305,433 \pm 115,971$ \\
\hline Neutrophil, \%, mean \pm SD & $75 \pm 14$ \\
\hline ESR, millimeters per hour, mean \pm SD & $46 \pm 29$ \\
\hline C-reactive protein, $\mathrm{mg} / \mathrm{L}$, mean $\pm \mathrm{SD}$ & $35 \pm 31$ \\
\hline $\mathrm{BUN}, \mathrm{mg} / \mathrm{dl}$, mean $\pm \mathrm{SD}$ & $15 \pm 11$ \\
\hline Creatinine, $\mathrm{mg} / \mathrm{dl}$, mean $\pm \mathrm{SD}$ & $1.13 \pm 0.76$ \\
\hline Aspatate aminotransferase, $U / L$, mean $\pm S D$ & $33 \pm 34$ \\
\hline Alanine aminotransferase, $\mathrm{U} / \mathrm{L}$, mean $\pm \mathrm{SD}$ & $37 \pm 45$ \\
\hline Total bilirubin, mg/dl, mean \pm SD & $1.4 \pm 3.9$ \\
\hline Albumin, mg/dl, mean \pm SD & $4.0 \pm 0.5$ \\
\hline \multicolumn{2}{|l|}{ Urinary tract infection (UTI) diagnosis } \\
\hline Acute pyelonephritis & $21(70 \%)$ \\
\hline Complicated UTI & $9(30 \%)$ \\
\hline Stroke with neurogenic bladder & 3 \\
\hline Catheter-related UTI & 2 \\
\hline Ureteric stone with hydronephrosis & 2 \\
\hline UTI in men & 2 \\
\hline Positive urine culture & $22(73 \%)$ \\
\hline E. coli & 11 \\
\hline ESBL producing E. coli & 4 \\
\hline $\begin{array}{l}\text { ESBL producing E. coli }+ \text { ESBL producing K. pneu- } \\
\text { moniae }\end{array}$ & 1 \\
\hline Enterobacter cloacae & 1 \\
\hline Enterococcus fecalis & 1 \\
\hline Klebseilla pneumoniae & 1 \\
\hline Morganella morganii & 1 \\
\hline MRSA & 1 \\
\hline Coagulase negative Staphylococcus & 1 \\
\hline \multicolumn{2}{|l|}{ Sensitivity to sitafloxacin, $n=22$} \\
\hline Sensitive & $19(86 \%)$ \\
\hline Intermediate & $1(5 \%)$ \\
\hline Resistant & $2(9 \%)$ \\
\hline
\end{tabular}

norfloxacin, cefotaxime, ceftazidime, and cefepime. Of 7 strains resisted to norfloxacin and ciprofloxacin, 5 strains were sensitive to sitafloxacin 2 strains resisted to sitafloxacin, including E. cloacae and K. pneumoniae.

In terms of treatment response at day 7 , among the 22 positive urine cultures at baseline visits, 21 (95\%) were microbiologically cured. Two of 21 patients were presumed 
to have a microbiological cure. The mean $\pm \mathrm{SD}$ white blood cell count in the complete blood count was $7710 \pm 3452$ cell $/ \mathrm{mm}^{3}$ and the mean \pm SD percentage of neutrophils was $58 \pm 11 \%$. The ESR was $50 \pm 30 \mathrm{~mm}$ per hour. The C-reactive protein was $13 \pm 18 \mathrm{mg} / \mathrm{L}$. By repeated measurement analysis, there was a significant decline in C-reactive protein from the baseline visit $(P<0.001)$ but not in ESR $(P=0.505)$. At day 14,29 of $30(97 \%)$ patients were clinically cured and 21 of $22(95 \%)$ patients were microbiological cured as shown in Fig. 1. One female patient with clinical failure was diagnosed to have acute pyelonephritis with ESBL-producing E. coli. This isolate was resistant to ciprofloxacin and norfloxacin but not sitafloxacin. Her clinical symptoms worsened after 5 days of treatment, so sitafloxacin was switched to intravenous ertapenem. In terms of tolerability, none of the patients discontinued sitafloxacin due to adverse events. At day 7, the mean \pm SD aspartate aminotransferase was $22 \pm 7 \mathrm{U} / \mathrm{L}$ and the mean $\pm \mathrm{SD}$ alanine aminotransferase was $30 \pm 17 \mathrm{U} / \mathrm{L}$. By repeated measurement analysis, there were no differences in aspartate aminotransferase $(P=0.105)$ and alanine aminotransferase $(P=0.390)$ between the baseline visit and day 7 . No initially isolated uropathogens developed resistance to sitafloxacin during treatment.

\section{Discussion}

In the treatment of complicated urinary tract infections and acute pyelonephritis, determining the underlying disease and prompt and effective antibiotic treatment are essential. E. coli was the most commonly isolated pathogen and few gram-positive uropathogens were isolated in the present study. Of note, one-third of them were ESBLproducing strains. In addition, a previous report in Thais demonstrated that the incidence of ESBL-producing $E$. coli septicemia was 9.9 cases per 10,000 hospital admissions. The risk factors associated with ESBL-producing E. coli septicemia were hospital acquisition, previous

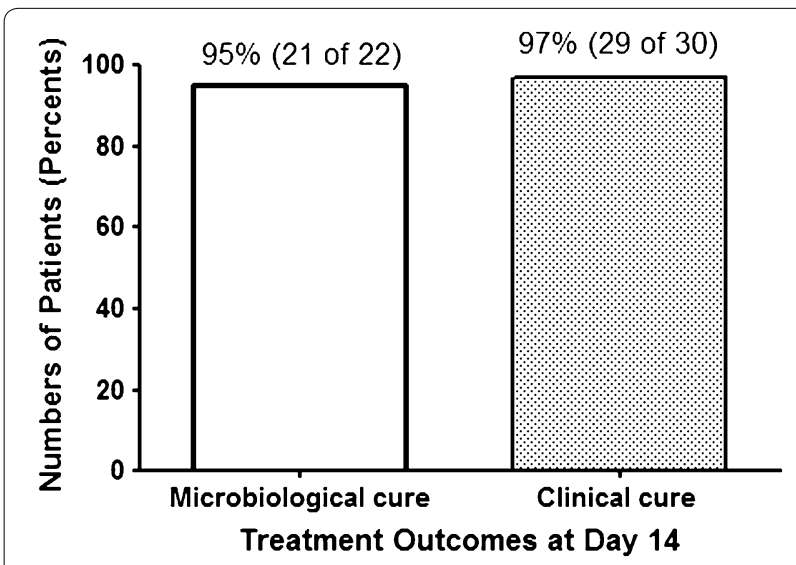

Fig. 1 Treatment outcomes at day 14 after sitafloxacin therapy use of a fluoroquinolone, and the use of a central venous catheter (Anunnatsiri et al. 2012). Our findings highlight a concern that there was a high rate of drug-resistant uropathogens among the causative uropathogens and a broad range of uropathogens in this setting. This may be partly explained by the fact that this study involved patients with complicated urinary tract infections. In general, drug-resistant uropathogens are more commonly isolated, and the causative uropathogens vary widely when compared to isolates from patients with uncomplicated urinary tract infections. Nonetheless, almost all patients' infections were microbiologically eradicated.

Sitafloxacin demonstrated high rates of microbiological and clinical success in this study, i.e., $>90 \%$. Kawada and colleagues demonstrated that $>90 \%$ clinical efficacy was achieved with sitafloxacin $50 \mathrm{mg}$ twice daily for 7 days (Kawada et al. 2008a). In addition, a previous study demonstrated that $>80 \%$ of isolates from patients with complicated urinary tract infections remained susceptible to sitafloxacin, while the rates for levofloxacin and third-generation cephalosporins were lower (Kawada et al. 2008b). Fluoroquinolone resistance in $E$. coli mainly develops by mutations of DNA gyrase and topoisomerase IV (Hoshino et al. 1994). The recommended sitafloxacin dosage for treatment of acute pyelonephritis and complicated urinary tract infections was 50-100 mg twice daily for 7-14 days. The inhibitory activity of sitafloxacin against such enzymes was greater than that of fluoroquinolones (Okumura et al. 2008; Onodera et al. 1999). The MIC90 of sitafloxacin, levofloxacin, ciprofloxacin, and moxifloxacin against $E$. coli clinical isolates were $1-2,16,16-32$, and $16-32 \mu \mathrm{g} / \mathrm{mL}$, respectively (Keating 2011). For fluoroquinolone, the maximum concentration (Cmax): minimum inhibitory concentration (MIC) ratio and area under the curve (AUC):MIC ratio are appropriate parameters to predict activity and likelihood of developing drug resistance (Keating 2011). A previous study demonstrated that sitafloxacin $50 \mathrm{mg}$ oral twice daily achieving the Cmax:MIC ratio $>5$ were associated with eradication rate of $96 \%$ in respiratory tract pathogen. (Kohno et al. 2013) The dosage of sitafloxacin $100 \mathrm{mg}$ oral twice daily achieved a higher Cmax. In addition, mutation prevention concentration (MPC) of sitafloxacin had a lower concentration level than other quinolones. This suggests that sitafloxacin has a higher barrier to developing resistance and the majority of levofloxacin-resistant E. coli remains susceptible to sitafloxacin. Two sitafloxacin-resistant isolates were found in the present study without treatment failure. In addition, a double dose of sitafloxacin was allowed to treat these patients to overcome this effect. Previous studies showed that sitafloxacin was more active than levofloxacin, ciprofloxacin and 
moxifloxacin against bacteria isolated from Thai and Japanese patients including ESBL-producing gram-negative strains (Tiengrim et al. 2012; Amano et al. 2013; Nakamura et al. 2014; Matsumoto et al. 2012). Nevertheless, drug-resistance is one of the major challenges in treating these urinary tract infections due to an increased incidence of fluoroquinolone-resistant uropathogens (Czaja et al. 2007).

The most frequently reported adverse reactions of sitafloxacin included diarrhea and transaminitis (Matsumoto et al. 2012). Diarrhea symptoms were usually mild, as in previous reports (Hooton 2003; Matsumoto et al. 2012). None of the patients discontinued sitafloxacin due to adverse events. Likewise, no elevation of aspartate aminotransferase or alanine aminotransferase was found $(P>0.05)$. Therefore, the overall tolerability profile of sitafloxacin is favorable. A limitation of the present study is that the sample size was relatively small and there were no comparators. Additional larger studies and longer follow-up periods are needed to confirm our findings. In addition, the minimum inhibitory concentration (MIC) of sitafloxacin was not addressed. However, the correlation of the inhibition zone diameter of sitafloxacin as determined by the disk diffusion method and the MIC determined by the agar dilution method has been demonstrated (Thamlikitkul and Tiengrim 2014).

Oral sitafloxacin 50-100 mg twice daily administered for 7-14 days was effective in the treatment of complicated urinary tract infections and acute pyelonephritis. All patients tolerated sitafloxacin well. This result supports the use of oral sitafloxacin against such infections. However, further larger studies are required to confirm these results.

\section{Authors' contributions}

WM and SW conducted the study as well as reviewed and drafted manuscript. Both authors read and approved the final manuscript.

\section{Acknowledgements}

We thank all patients who participated in this study. This study was funded by a grant from Daiichi Sankyo (Thailand) Ltd.

\section{Competing interests}

The authors declare that they have no competing interests.

Received: 3 February 2015 Accepted: 23 March 2016

Published online: 05 April 2016

\footnotetext{
References

Amano A, Matsuzaki K, Kishi N, Koyama H, Hasegawa M, Ikeda F, Matsumoto T, Yamaguchi H, Okutani Y (2013) In vitro activity of sitafloxacin against clinical isolates in 2012. Jpn J Antibiot 66(6):311-330

Anunnatsiri S, Towiwat P, Chaimanee P (2012) Risk factors and clinical outcomes of extended spectrum beta-lactamase (ESBL)-producing Escherichia coli septicemia at Srinagarind University Hospital, Thailand. Southeast Asian J Trop Med Public Health 43(5):1169-1177
}

Czaja CA, Scholes D, Hooton TM, Stamm WE (2007) Population-based epidemiologic analysis of acute pyelonephritis. Clin Infect Dis Off Publ Infect Dis Soc Am 45(3):273-280

Grabe M, Bartoletti R, Bjerklund-Johansen TE, Çek HM, Pickard RS, Tenke P, Wagenlehner F, Wullt B (2013) Guidelines on urological infections. http:// www.uroweb.org/gls/pdf/18_Urologicalinfections_LR.pdf

Gupta K, Hooton TM, Naber KG, Wullt B, Colgan R, Miller LG, Moran GJ, Nicolle $L E$, Raz R, Schaeffer AJ et al (2011) International clinical practice guidelines for the treatment of acute uncomplicated cystitis and pyelonephritis in women: A 2010 update by the Infectious Diseases Society of America and the European Society for Microbiology and Infectious Diseases. Clin Infect Dis Off Publ Infect Dis Soc Am 52(5):e103-e120

Hooton TM (2003) The current management strategies for communityacquired urinary tract infection. Infect Dis Clin North Am 17(2):303-332

Hoshino K, Kitamura A, Morrissey I, Sato K, Kato J, Ikeda H (1994) Comparison of inhibition of Escherichia coli topoisomerase IV by quinolones with DNA gyrase inhibition. Antimicrob Agents Chemother 38(11):2623-2627

Kawada Y, Yasuda M, Tanaka K, Monden K, Akasaka S, Egashira T, Kaku M, Hori S (2008a) Dose-comparative atudy of sitafloxacin in complicated urinary tract infections. Jpn J Chemother 56:92-102

Kawada Y, Ishihara S, Matsui T, Tsugawa M, Matsumoto T, Watanabe K, Nakashima M (2008b) Comparative study on sitafloxacin and levofloxacin in complicated urinary tract infections. Jpn J Chemother 56:81-91 Keating GM (2011) Sitafloxacin: in bacterial infections. Drugs 71(6):731-744 Kohno S, Niki Y, Kadota J, Yanagihara K, Kaku M, Watanabe A, Aoki N, Hori S, Fujita J, Tanigawara Y (2013) Clinical dose findings of sitafloxacin treatment: pharmacokinetic-pharmacodynamic analysis of two clinical trial results for community-acquired respiratory tract infections. J Infect Chemother Off J Jpn Soc Chemother 19(3):486-494

Matsumoto T, Yamaguchi H, Uchino K, Takahashi M, Kodama H, Hamajima S, Yonemochi R, Fujita S, Takita A, Yamanouchi N et al (2012) Efficacy and safety of sitafloxacin in patients with urinary tract infections. Jpn J Antibiot 65(6):365-380

Nakamura T, Komatsu M, Yamasaki K, Fukuda S, Higuchi T, Ono T, Nishio H, Sueyoshi N, Kida K, Satoh K et al (2014) Susceptibility of various oral antibacterial agents against extended spectrum beta-lactamase producing Escherichia coli and Klebsiella pneumoniae. J Infect Chemother Off J Jpn Soc Chemother 20(1):48-51

Nakashima M, Uematsu T, Kosuge K, Umemura K, Hakusui H, Tanaka M (1995) Pharmacokinetics and tolerance of DU-6859a, a new fluoroquinolone, after single and multiple oral doses in healthy volunteers. Antimicrob Agents Chemother 39(1):170-174

O'Grady J, Briggs A, Atarashi S, Kobayashi H, Smith RL, Ward J, Ward C, Milatovic D (2001) Pharmacokinetics and absolute bioavailability of sitafloxacin, a new fluoroquinolone antibiotic, in healthy male and female Caucasian subjects. Xenobiot Fate Foreign Compd Biol Syst 31(11):811-822

Okumura R, Hirata T, Onodera Y, Hoshino K, Otani T, Yamamoto T (2008) Dualtargeting properties of the 3-aminopyrrolidyl quinolones, DC-159a and sitafloxacin, against DNA gyrase and topoisomerase IV: contribution to reducing in vitro emergence of quinolone-resistant Streptococcus pneumoniae. J Antimicrob Chemother 62(1):98-104

Onodera Y, Uchida Y, Tanaka M, Sato K (1999) Dual inhibitory activity of sitafloxacin (DU-6859a) against DNA gyrase and topoisomerase IV of Streptococcus pneumoniae. J Antimicrob Chemother 44(4):533-536

Payne GS, Collins DJ, Loynds P, Mould G, Murphy PS, Dzik-Jurasz AS, Kessar P, Haque N, Yamaguchi M, Atarashi S et al (2005) Quantitative assessment of the hepatic pharmacokinetics of the antimicrobial sitafloxacin in humans using in vivoF magnetic resonance spectroscopy. Br J Clin Pharmacol 59(2):244-248

Polwichai P, Dejsirilert S, Panpetch S, Sawanpanyalert P, Aswapokee N, Mootsikapun P (2009) Antimicrobial resistance of Escherichia coli isolated from urine in Thailand from 2000 to 2005. J Med Assoc Thail 92(Suppl 4):S59-S67

Singh KP, Li G, Mitrani-Gold FS, Kurtinecz M, Wetherington J, Tomayko JF, Mundy LM (2013) Systematic review and meta-analysis of antimicrobial treatment effect estimation in complicated urinary tract infection. Antimicrob Agents Chemother 57(11):5284-5290

Thamlikitkul V, Tiengrim S (2014) In vitro susceptibility test of sitafloxacin against resistant gram-negative bacilli isolated from Thai patients by disk diffusion method. J Med Assoc Thail 97(Suppl 3):S7-12 
Tiengrim S, Phiboonbanakit D, Thunyaharn S, Tantisiriwat W, Santiwatanaku S, Susaengrat W, Srisurat N, Malithong A, Srisangchan P, Thamlikitkul $\checkmark$ (2012) Comparative in vitro activity of sitafloxacin against bacteria isolated from Thai patients with urinary tract infections and lower respiratory tract infections. J Med Assoc Thail 95(Suppl 2):S6-17

\section{Submit your manuscript to a SpringerOpen ${ }^{\odot}$} journal and benefit from:

- Convenient online submission

- Rigorous peer review

- Immediate publication on acceptance

- Open access: articles freely available online

- High visibility within the field

- Retaining the copyright to your article

Submit your next manuscript at $>$ springeropen.com 